\title{
Coagulation Process
}

National Cancer Institute

\section{Source}

National Cancer Institute. Coagulation Process. NCI Thesaurus. Code C21045.

Any of the sequential processes by which coagulation factors interact to form a fibrin clot. 